\title{
Influence of breastfeeding on maternal blood pressure at one month postpartum
}

\author{
This article was published in the following Dove Press journal: \\ International Journal of Women's Health \\ 10 July 2012 \\ Number of times this article has been viewed
}

\author{
Satoko Ebina' \\ Ikuo Kashiwakura² \\ 'Department of Disability and Health, \\ ${ }^{2}$ Department of Radiological Life \\ Sciences, Hirosaki University \\ Graduate School of Health Sciences, \\ Hirosaki, Japan
}

Background: The benefits of breastfeeding for improved health and developmental outcomes in mothers and their infants have been widely recognized. The purpose of the present study was to assess whether feeding modes influence maternal blood pressure at one month postpartum. Methods: The pregnancy charts of 407 women who delivered at a birthing center in rural Japan between August 1998 and September 2007 were analyzed. The criteria for inclusion were lowrisk, full-term pregnancy (duration, 37-42 weeks) resulting in spontaneous vaginal deliveries, intrapartum hemorrhage $<500 \mathrm{~mL}$, and a healthy infant (Apgar score $\geq 8$ at one minute).

Results: The subjects were classified into three groups based on feeding modes. The proportion of each mode was $28.3 \%$ in the breastfeeding group, $56.5 \%$ in the mixed-feeding group, and $15.2 \%$ in the formula-feeding group. The systolic blood pressure (SBP) in mothers at one month postpartum for each feeding mode was $118.4 \pm 8.7 \mathrm{mmHg}$ in the breastfeeding group, $120.6 \pm 9.3 \mathrm{mmHg}$ in the mixed-feeding group, and $122.0 \pm 9.9 \mathrm{mmHg}$ in the formula-feeding group. SBP at one month postpartum in the breastfeeding group was significantly lower than that in the other groups. No significant differences were observed in diastolic blood pressure in the three groups at one month postpartum.

Conclusion: Breastfeeding resulted in lower SBP in mothers at one month postpartum compared with those using other feeding modes, thus indicating an effect of breastfeeding on maternal blood pressure.

Keywords: breastfeeding, blood pressure, feeding mode, postpartum

\section{Introduction}

Human milk is species-specific and contains optimal nutrients, growth factors, and immunological components beneficial for infants. ${ }^{1}$ Breastfeeding in infants has short-term benefits, such as prevention of infectious diseases, including diarrhea, ${ }^{2-5}$ respiratory tract infection, ${ }^{6-9}$ and otitis media. ${ }^{10,11}$ Recent studies have reported that the long-term health benefits of breastfeeding in infants include reduction in the risk of adult diseases, such as obesity, ${ }^{12,13}$ hypertension, ${ }^{14,15}$ and type 1 diabetes mellitus. ${ }^{16,17}$ In addition, other studies have suggested that the long-term health benefits of breastfeeding for mothers include prevention of the development of ovarian ${ }^{18-20}$ and breast cancer $^{21,22}$ and type 2 diabetes mellitus. ${ }^{20}$ Furthermore, from an economic viewpoint, breastfeeding is less expensive than formula-feeding. ${ }^{23}$

Milk production initially occurs as a result of endocrine (prolactin, cortisol, thyroid-stimulating hormone, prolactin-inhibiting factor, oxytocin) activity. ${ }^{24}$ Among these physiological factors, oxytocin is released in a pulsatile fashion from the anterior pituitary gland as a result of nipple/areola stimulation. The main role of oxytocin is
Department of Radiological Life Sciences, Hirosaki University Graduate School of Health Sciences, 66-I Hon-cho, Hirosaki 036-8564, Japan

Tel +8I I 72395938

Fax +8II 72395938

Email ikashi@cc.hirosaki-u.ac.jp 
maintenance of lactogenesis, as well as decreased postpartum bleeding and more rapid uterine involution. In addition, it also functions as a neurotransmitter, sedative, and promoter of mother-child attachment. ${ }^{25-27}$ Johnston and Amico reported that plasma oxytocin levels in mothers who were exclusively breastfeeding were higher than those who were formulafeeding, and basal plasma oxytocin levels were maintained at a high level. ${ }^{28}$ Light et al suggested that oxytocin decreases blood pressure; mothers with high oxytocin levels had lower blood pressure than those with low oxytocin levels. ${ }^{29}$ In addition, Jonas et al reported that both systolic blood pressure (SBP) and diastolic blood pressure (DBP) fall during breastfeeding. ${ }^{30}$ However, although the relationship between breastfeeding and blood pressure has been studied to a reasonable extent, not enough evidence in terms of a link between breastfeeding and lower blood pressure has yet been obtained. In particular, little information is available on whether blood pressure differs in women among various feeding modes, including breastfeeding, mixed-feeding, and formula-feeding. An understanding of the relationship between breastfeeding and maternal blood pressure is very important for long-term maternal health benefits and disease prevention. The purpose of the present study was to assess whether feeding modes influence maternal blood pressure at one month postpartum.

\section{Materials and methods Study population}

The present retrospective chart review was conducted on the pregnancy charts of 407 women who delivered at a birthing center located in Aomori Prefecture, Japan. This study was conducted in accordance with the principles of the Declaration of Helsinki (Seoul 2008) and the ethical guidelines for epidemiological research provided by the Ministry of Education, Culture, Sports, Science, and Technology as well as the Ministry of Health, Labour, and Welfare in Japan (2008). All data used in the present study were coded and obtained from the medical records of subjects without disclosing their identity from the medical records. During the period from August 1998 until the end of September 2007, 579 pregnancy records of women who had a singleton pregnancy and delivered a live infant were studied. The inclusion criteria were low-risk, full-term pregnancy (duration 37-42 weeks) resulting in a spontaneous vaginal delivery, intrapartum hemorrhage $<500 \mathrm{~mL}$, and a healthy infant (Apgar score $\geq 8$ at one minute). Mothers with chronic diseases (eg, diabetes, hypertension, hyperthyroidism), gestational diabetes, and pregnancy-induced hypertension were excluded from the study. Records with unknown or missing data regarding obstetric factors were not included. A total of 407 cases were finally available for analysis.

\section{Perinatal factors}

Perinatal factors extracted from the pregnancy charts were maternal age, parity, self-reported prepregnancy weight, prepregnancy body mass index, gestational weight gain, blood pressure, chronic diseases, delivery mode, duration of pregnancy, duration of labor, neonatal gender, neonatal weight and height, Apgar score at one minute, admission to hospital, and first month checkup (maternal weight, blood pressure, feeding modes, infant weight).

\section{Feeding modes}

Subjects were divided into three groups according to feeding modes at one month postpartum. The first group was exclusively breastfeeding and the mothers gave breast milk only; the second group was mixed-feeding with breast milk and infant formula; and the third group was formula-feeding with infant formula only. Each feeding mode at one month postpartum was determined by self-assessment from mothers.

\section{Statistical analysis}

Statistical analysis was performed using SPSS software, version 16.0 (SPSS Japan Inc, Tokyo, Japan) for Windows. Descriptive statistics are shown as the arithmetic mean \pm standard deviation. All data showed a normal distribution. A twosample $t$-test, one-way analysis of variance, and Tukey's honestly significant difference test were performed to determine differences across the three groups. The $\chi^{2}$ statistic was used to analyze categorical variables. Univariate analysis was performed using Pearson's correlation coefficient. Multiple linear regression analysis was performed to determine any association between SBP (object functions) and maternal factors (explanatory variables). A value of $P<0.05$ was considered to be statistically significant.

\section{Results}

\section{Characteristics of study population}

Characteristics of the study population are summarized in Table 1 . The study population was classified into three groups depending upon the feeding mode, ie, breastfeeding $28.3 \%$, mixed-feeding $56.5 \%$, and formula-feeding $15.2 \%$. The overall smoking rate was $18.2 \%$, and the values in each group were $7.8 \%, 20.9 \%$, and $27.4 \%$, respectively, indicating that the smoking rate in the breastfeeding group was significantly lower than that in the other groups. No significant difference 
Table I Summary and comparison of characteristics in the feeding modes

\begin{tabular}{|c|c|c|c|c|c|c|c|c|}
\hline \multirow[t]{3}{*}{ Maternal/infant factors } & \multicolumn{8}{|c|}{ Feeding modes group } \\
\hline & \multicolumn{2}{|c|}{$\begin{array}{l}\text { All population } \\
n=407(100 \%)\end{array}$} & \multicolumn{2}{|c|}{$\begin{array}{l}\text { Breastfeeding } \\
\mathrm{n}=\mathrm{I} / 5(28.3 \%)\end{array}$} & \multicolumn{2}{|c|}{$\begin{array}{l}\text { Mixed-feeding } \\
n=230(56.5 \%)\end{array}$} & \multicolumn{2}{|c|}{$\begin{array}{l}\text { Formula-feeding } \\
n=62(15.2 \%)\end{array}$} \\
\hline & Mean & SD & Mean & SD & Mean & SD & Mean & SD \\
\hline Maternal age years ${ }^{\mathrm{b}}$ & 26.7 & 4.5 & 26.7 & 4.1 & 26.6 & 4.6 & 26.7 & 4.7 \\
\hline Nulliparous ${ }^{c}$ & 154 & 37.8 & 43 & 37.4 & 91 & 39.6 & 20 & 32.3 \\
\hline Smokers ${ }^{c}$ & 74 & 18.2 & 9 & 7.8 & 48 & 20.9 & 17 & $27.4 * *$ \\
\hline Prepregnancy weight kg ${ }^{\mathrm{b}}$ & 53.4 & 8.5 & 52.6 & 6.8 & 53.6 & 9.3 & 54.2 & 8.3 \\
\hline Prepregnancy body mass index $x^{a, b}$ & 21.2 & 3.2 & 20.9 & 2.4 & 21.4 & 3.6 & 21.4 & 3.4 \\
\hline Delivery weight & 65.2 & 8.7 & 64.3 & 7.4 & 65.6 & 9.1 & 65.4 & 9.4 \\
\hline Gestational weight gain $\mathrm{kg}^{\mathrm{b}}$ & 11.8 & 4.0 & 11.7 & 3.5 & 12.0 & 4.4 & 11.2 & 3.7 \\
\hline Duration of pregnancy weeks ${ }^{b}$ & 39.5 & 1.2 & 39.5 & I.I & 39.6 & 1.2 & 39.3 & 1.1 \\
\hline Birth weight $g^{b}$ & 3213.5 & 373.1 & 3200.2 & 321.9 & 3226.1 & 403.6 & 3188.2 & 345.5 \\
\hline One-minute Apgar score ${ }^{\mathrm{b}}$ & 9.8 & 0.4 & 9.9 & 0.4 & 9.8 & 0.4 & 9.7 & 0.5 \\
\hline $\begin{array}{l}\text { Maternal weight at one month } \\
\text { postpartum } \mathrm{kg}^{\mathrm{b}}\end{array}$ & 57.9 & 8.3 & 57.1 & 7.1 & 58.3 & 8.8 & 57.8 & 8.8 \\
\hline Postpartum weight loss kg & 7.3 & 2.3 & 7.2 & 2.1 & 7.3 & 2.3 & 7.6 & 2.5 \\
\hline Infant weight at one month $g^{b}$ & 4510.1 & 455.7 & 4496.2 & 448.5 & 4523.5 & 476.0 & 4486.0 & 392.5 \\
\hline
\end{tabular}

Notes: aBody mass index, weight in kilograms divided by the square of the height in meters $\left(\mathrm{kg} / \mathrm{m}^{2}\right)$; ' one-way analysis of variance, not significant; ' $\mathrm{p}$ resented as number and percent and analyzed with the $\chi^{2}$ test: $* * p<0.01$.

Abbreviation: SD, standard deviation.

was observed between feeding modes and maternal/infant factors, except for maternal smoking status.

\section{Assessment of feeding modes and blood pressure}

Results for maternal blood pressure at one month postpartum obtained for each feeding mode are shown in Figure 1. The mean SBP value $118.4 \pm 8.7 \mathrm{mmHg}$ in the breastfeeding group, $120.6 \pm 9.3 \mathrm{mmHg}$ in the mixed-feeding group, and $122.0 \pm 9.9 \mathrm{mmHg}$ in the formula-feeding group, demonstrating that blood pressure increased in a stepwise manner across the groups. The breastfeeding group showed the lowest value among the three groups, whereas no significant differences in one-month postpartum DBP were observed among the three groups. However, SBP and DBP values of these groups, as shown in Figure 2, showed no statistically significant differences in the third trimester. In addition, multiple linear regression analysis identified maternal weight at one month postpartum, feeding modes, and parity as independent predictive factors for SBP elevation at one month postpartum; however, the value of $R^{2}$ was low $\left(R^{2}=0.09\right.$, one-way analysis of variance; $P<0.001)$.
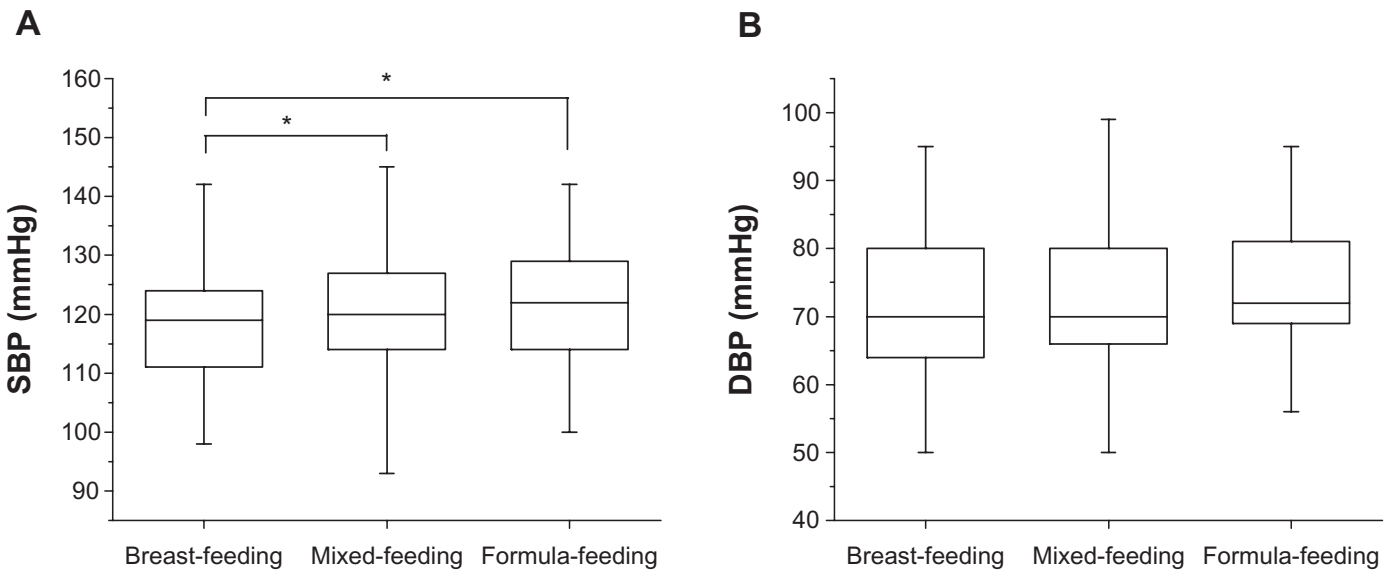

Figure I Distribution of SBP and DBP at one month postpartum in three feeding modes, breastfeeding, mixed-feeding, and formula-feeding. SBP observed in the breastfeeding group was significantly lower than that in the other groups $(P<0.05)(\mathbf{A})$ No significant difference was observed in DBP. (B) One-way analysis of variance: $* P<0.05$.

Abbreviations: DBP, diastolic blood pressure; SBP, systolic blood pressure. 
A

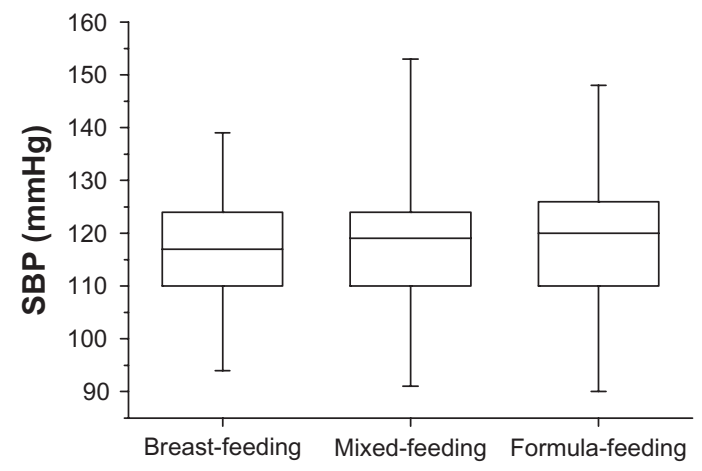

B

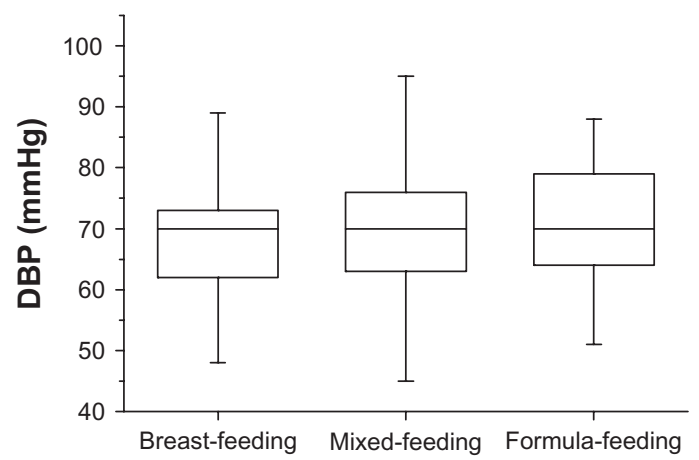

Figure 2 Distribution of SBP/DBP in the third trimester observed according to three feeding modes, namely breastfeeding, mixed-feeding, and formula-feeding. No statistically significant differences were observed in SBP and DBP between mothers who used any of the three feeding modes (A and B).

Abbreviations: DBP, diastolic blood pressure; SBP, systolic blood pressure.

\section{Relationship between maternal factors and blood pressure}

A positive weak correlation was observed between SBP at one month postpartum and prepregnancy weight $(\mathrm{r}=0.231$, $P<0.001)$, prepregnancy body mass index $(\mathrm{r}=0.214$, $P<0.001)$, delivery weight $(\mathrm{r}=0.249, P<0.001)$, and maternal weight at one month postpartum $(\mathrm{r}=0.250$, $P<0.001$, Table 2). However, no significant correlation was observed between SBP at one month postpartum and maternal age, gestational weight gain, duration of pregnancy, or postpartum weight loss (Table 2). Furthermore, multiple linear regression analysis was used to identify independent variables associated with elevated blood pressure. The mother's weight at one month postpartum, feeding mode, parity, and SBP in the third trimester of pregnancy were identified as variables that can independently predict increased SBP at one month postpartum $\left(R^{2}=0.14\right.$, one-way analysis of variance, $P<0.001$, data not shown), although $R^{2}$ was a low value. Because it may be considered that smoking

Table 2 Correlations between maternal factors and blood pressure

\begin{tabular}{llllll}
\hline & \multicolumn{2}{l}{$\begin{array}{l}\text { Third trimester } \\
\text { of pregnancy }\end{array}$} & & \multicolumn{2}{l}{$\begin{array}{l}\text { One month } \\
\text { postpartum }\end{array}$} \\
\cline { 2 - 3 } \cline { 6 - 7 } & SBP & DBP & & SBP & DBP \\
\hline Maternal age & 0.036 & -0.014 & & $0.133^{* *}$ & 0.049 \\
Duration of pregnancy & -0.015 & 0.063 & & -0.002 & 0.031 \\
Prepregnancy weight & $0.203^{* *}$ & 0.071 & & $0.23 I^{* *}$ & 0.096 \\
Prepregnancy BMI & $0.177^{* *}$ & 0.067 & & $0.214^{* *}$ & 0.059 \\
Delivery weight & $0.202^{* *}$ & 0.073 & & $0.249^{* *}$ & $0.146^{* *}$ \\
Gestational weight gain & 0.009 & 0.011 & & 0.043 & 0.043 \\
Maternal weight one month & $0.184^{* *}$ & 0.060 & & $0.250^{* *}$ & $0.143^{* *}$ \\
postpartum & & & & & \\
\hline
\end{tabular}

Notes: Pearson's correlation coefficient: $* P<0.05 ; * * P<0.01$.

Abbreviations: BMI, body mass index; DBP, diastolic blood pressure; SBP, systolic blood pressure. affected blood pressure as a confounding factor, the data were adjusted by smoking, and a regression analysis was conducted. As a result, delivery weight, parity, and feeding mode were identified as factors $\left(R^{2}=0.076\right.$, one-way analysis of variance, $P<0.001$, data not shown).

Next, the effects of parity and maternal smoking on blood pressure were analyzed (Table 3). SBP in multiparous mothers was higher than that in primiparous mothers $(121.1 \pm 9.0 \mathrm{mmHg}$ versus $118.7 \pm 9.5 \mathrm{mmHg}, P<0.05)$. At this time, the mean maternal age of nulliparous and multiparous women was $24.2 \pm 3.9$ years and $28.1 \pm 4.2$ years, respectively, showing that maternal age in multiparous women was significantly higher than that in nulliparous women $(P<0.001)$. In contrast, smoking did not affect blood pressure, although the mean maternal age of nonsmokers was significantly higher than that of smokers $(26.9 \pm 4.5$ years versus $25.4 \pm 4.4$ years, $P<0.05)$. However, parity did not affect blood pressure in either case (data not shown).

\section{Discussion}

In this retrospective study, the pregnancy charts of 407 women who delivered at a birthing center in rural Japan between August 1998 and September 2007 were analyzed. When blood pressure in each group was compared, onemonth postpartum SBP in the breastfeeding group was significantly lower than that in the other groups (Figure 1). At that time, various factors such as maternal age, prepregnancy weight, prepregnancy body mass index, delivery weight, and maternal weight at one month postpartum correlated with SBP (Table 2). Generally, aging and smoking cause high blood pressure. Actually, maternal age in the multiparous group was significantly higher than that in the nulliparous group, which showed a lower SBP than that in the multiparous group (Table 3). The present results showed that the smoking rate 
Table 3 Influence of parity and maternal smoking status on blood pressure

\begin{tabular}{|c|c|c|c|c|c|}
\hline & \multirow[t]{2}{*}{ Mean age } & \multicolumn{2}{|c|}{ Third trimester of pregnancy } & \multicolumn{2}{|c|}{ One month postpartum } \\
\hline & & SBP & DBP & SBP & DBP \\
\hline $\begin{array}{l}\text { Nulliparous } \\
(\mathrm{n}=154)\end{array}$ & $24.2(3.9)^{*}$ & $117.2(9.9)$ & $69.6(8.7)$ & $118.7(9.5)$ & $71.8(9.8)$ \\
\hline $\begin{array}{l}\text { Multiparous } \\
(\mathrm{n}=253)\end{array}$ & $28.1(4.2)^{*}$ & $117.3(10.0)$ & $69.7(9.2)$ & $|2| . \mid(9.0)^{*}$ & $73.0(10.0)$ \\
\hline $\begin{array}{l}\text { Nonsmokers } \\
(\mathrm{n}=333)\end{array}$ & $26.9(4.4)^{*}$ & $117.4(10.0)$ & $69.3(9.1)$ & I $20.3(9.3)$ & $72.7(9.7)$ \\
\hline $\begin{array}{l}\text { Smokers } \\
(n=74)\end{array}$ & $25.4(4.5)^{*}$ & $117.5(9.9)$ & $71.5(8.1)$ & II $9.7(9.3)$ & $71.7(10.6)$ \\
\hline
\end{tabular}

Notes: Values in parentheses are the standard deviation. A statistically significant difference was found between nulliparous and multiparous and nonsmokers and smokers by the two-sample $t$-test $* P<0.05$.

Abbreviations: DBP, diastolic blood pressure; SBP, systolic blood pressure.

in the breastfeeding group was significantly lower than that in the other groups (Table 1), indicating that mothers in the mixed-feeding and formula-feeding groups were more likely to be smokers. Therefore, it may be considered that smoking affected blood pressure as a confounding factor. However, no significant relationships were observed with any factors, suggesting that a direct effect of smoking does not affect the lower SBP caused by breastfeeding in mothers at one month postpartum. Lee et al reported that women who breastfeed for 1-6 months have a lower risk of hypertension than those who do not breastfeed. ${ }^{31}$ Jonas et al and Altemus et al reported that both SBP and DBP reduce during a breastfeeding session, and that blood pressure before breastfeeding decreases during at least the first 6 months of breastfeeding in a homelike environment. ${ }^{30,32}$ Under these circumstances, there is a possibility that breastfeeding reduces blood pressure, particularly SBP, and that aging acted as a factor that upregulated blood pressure in the present population.

Oxytocin is released in a pulsatile manner from the anterior pituitary gland because of nipple/areolar stimulation. Previous studies have reported that oxytocin levels in breastfeeding mothers are higher than those in mixed-feeding mothers. ${ }^{28}$ Additionally, mothers with high oxytocin levels have lower blood pressure than those with low oxytocin levels. ${ }^{29}$ In animal studies, frequent oxytocin administration induces calm and long-term antistress effects, such as lowering of blood pressure in rats. ${ }^{33,34}$ Because mothers in the breastfeeding group fed their infants several times per day, oxytocin was released whenever the infant suckled the breast; thus, oxytocin was repeatedly released during breastfeeding. Therefore, these findings suggest that blood pressure in breastfeeding mothers decreased in response to oxytocin release, and that these mothers were likely to benefit from oxytocin at least while breastfeeding their infant. In the present study, plasma levels of oxytocin in mothers were unknown, because this study was a retrospective chart review. Additional approaches will be needed to clarify these issues.

The present results showed that the exclusive breastfeeding rate at one month was $28.3 \%$ (Table 1). In 1989, the World Health Organization/United Nations Children's Fund released a joint document called "The Ten Steps to Successful Breastfeeding". ${ }^{35}$ The American Academy of Pediatrics ${ }^{23}$ and World Health Organization ${ }^{36}$ both recommend exclusive breastfeeding for infants in the first 6 months of life. In a US national survey conducted in 2001, 33\% of infants were breastfed (exclusive breastfeeding 17\%) at the age of 6 months..$^{37}$ In Japan, breastfeeding has been promoted since 1989, according to the abovementioned guidelines. According to a national Japanese study in 2005, 42.4\% of infants at the age of one month, $38.0 \%$ at 3 months, and $34.7 \%$ at 6 months were exclusively breastfed. ${ }^{38}$ The breastfeeding rate obtained herein was much lower than the national average of Japan reported in 2005. These results may be because of regional characteristics and lack of knowledge or motivation for breastfeeding.

It is well known that breast milk is the ideal food for infants. Numerous worldwide studies have demonstrated improved health and developmental outcomes in breastfed infants and their mothers. The present study showed that breastfeeding resulted in lower SBP in mothers at one month postpartum compared with those using other feeding modes. Although the present study was performed in one specific district in Japan, the results support previous findings that breast feeding may induce long-term positive effects on maternal health. One important benefit of breast feeding is the prevention of adult diseases, and since chronic diseases, including metabolic disorders, are one of the largest causes of death in adults, promoting breastfeeding is essential. Thus, promoting breastfeeding is recommended, and further studies 
on the benefits of breast feeding for both the mother and child are needed to achieve this aim.

\section{Acknowledgments}

We are indebted to the midwives of the Fukushi Birth Center for collecting the pregnancy charts. This study was supported by a grant for Hirosaki University Institutional Research in 2011.

\section{Disclosure}

The authors report no conflicts of interest in this work.

\section{References}

1. Prentice A. Constituents of human milk. Available at: http://archive. unu.edu/unupress/food/8F174e/ 8F174E04.htm\#Constituents of human milk. Accessed June 14, 2012.

2. Howie PW, Forsyth JS, Ogston SA, Clark A, Florey CD. Protective effect of breast feeding against infection. BMJ. 1990;300:11-16.

3. Clemens J, Rao M, Ahmed F, et al. Breast-feeding and the risk of lifethreatening rotavirus diarrhea: prevention or postponement? Pediatrics. 1993;92:680-685.

4. Lopez-Alarcon M, Villalpando S, Fajardo A. Breast-feeding lowers the frequency and duration of acute respiratory infection and diarrhea in infants under six months of age. J Nutr. 1997;127:436-443.

5. Bhandari N, Bahl R, Mazumdar S, Martines J, Black RE, Bhan MK. Effect of community-based promotion of exclusive breastfeeding on diarrhoeal illness and growth: a cluster randomized controlled trial. Infant Feeding Study Group. Lancet. 2003;361:1418-1423.

6. Blaymore Bier J, Oliver T, Ferguson A, Vohr BR. Human milk reduces outpatient upper respiratory symptoms in premature infants during their first year of life. J Perinatol. 2002;22:354-359.

7. Bachrach VR, Schwarz E, Bachrach LR. Breastfeeding and the risk of hospitalization for respiratory disease in infancy: a meta-analysis. Arch Pediatr Adolesc Med. 2003;157:237-243.

8. Chantry CJ, Howard CR, Auinger P. Full breastfeeding duration and associated decrease in respiratory tract infection in US children. Pediatrics. 2006;117:425-432.

9. Wright AL, Holberg CJ, Martinez FD, Morgan WJ, Taussig LM. Breast feeding and lower respiratory tract illness in the first year of life. Group Health Medical Associates. BMJ. 1989;299:946-949.

10. Owen MJ, Baldwin CD, Swank PR, Pannu AK, Johnson DL, Howie VM. Relation of infant feeding practices, cigarette smoke exposure, and group child care to the onset and duration of otitis media with effusion in the first two years of life. J Pediatr. 1993;123:702-711.

11. Aniansson G, Alm B, Andersson B, et al. A prospective cohort study on breast-feeding and otitis media in Swedish infants. Pediatr Infect Dis J. 1994;13:183-188.

12. Von Kries R, Koletzko B, Sauerwald T, et al. Breast feeding and obesity: cross sectional study. BMJ. 1999;319:147-150.

13. Owen CG, Martin RM, Whincup PH, Smith GD, Cook DG. Effect of infant feeding on the risk of obesity across the life course: a quantitative review of published evidence. Pediatrics. 2005;115:1367-1377.

14. Singhal A, Cole TJ, Lucas A. Early nutrition in preterm infants and later blood pressure: two cohorts after randomised trials. Lancet. 2001;357: 413-419.

15. World Health Organization. Evidence on the long-term effects of breastfeeding. Systematic reviews and meta-analysis. Available at: http:// www.who.int/maternal_child_adolescent/documents/9241595230/en/. Accessed June 14, 2012.

16. Virtanen SM, Räsänen L, Aro A, et al. Infant feeding in Finnish children less than $7 \mathrm{yr}$ of age with newly diagnosed IDDM. Childhood Diabetes in Finland Study Group. Diabetes Care. 1991;14:415-417.
17. Gerstein HC. Cow's milk exposure and type I diabetes mellitus. A critical overview of the clinical literature. Diabetes Care. 1994;17: 13-19.

18. Gwinn ML, Lee NC, Rhodes PH, Layde PM, Rubin GL. Pregnancy, breast feeding, and oral contraceptives and the risk of epithelial ovarian cancer. J Clin Epidemiol. 1990;43:559-568.

19. Rosenblatt KA, Thomas DB. Lactation and the risk of epithelial ovarian cancer. WHO Collaborative Study of Neoplasia and Steroid contraceptives. Int J Epidemiol. 1993;22:192-197.

20. Stuebe A. The risks of not breastfeeding for mothers and infants. Rev Obstet Gynecol. 2009;2:222-231.

21. Labbok MH. Effects of breastfeeding on the mother. Pediatr Clin North Am. 2001;48:143-158.

22. Collaborative Group on Hormonal Factors in Breast Cancer. Breast cancer and breastfeeding: collaborative reanalysis of individual data from 47 epidemiological studies in 30 countries, including 50302 women with breast cancer and 96973 women without the disease. Lancet. 2002;360:187-195.

23. American Academy of Pediatrics. Breastfeeding and the use of human milk. Pediatrics. 2005;115:196-506.

24. Neville MC, Neifert MR, editors. Lactation: Physiology, Nutrition and Breast Feeding. New York, NY: Plenum Press; 1983.

25. Uvnäs-Moberg K. Oxytocin linked antistress effects - the relaxation and growth response. Acta Physiol Scand Suppl. 1997;640:38-42.

26. Uvnäs-Moberg K, Petersson M. Oxytocin, a mediator of anti-stress, well-being, social interaction, growth and healing. $Z$ Psychosom Med Psychother. 2005;51:57-80. German.

27. Nemsadze K, Silagava M. Neuroendocrine foundation of maternal-child attachment. Georgian Med News. 2010:21-26.

28. Johnston JM, Amico JA. A prospective longitudinal study of the release of oxytocin and prolactin in response to infant suckling in long term lactation. J Clin Endocrinol Metab. 1986;62:653-657.

29. Light KC, Smith TE, Johns JM, Brownley KA, Hofheimer JA, Amico JA. Oxytocin responsivity in mothers of infants: a preliminary study of relationships with blood pressure during laboratory stress and normal ambulatory activity. Health Psychol. 2000;19:560-567.

30. Jonas W, Nissen E, Ransjö-Arvidson AB, Wiklund I, Henriksson P, Uvnäs-Moberg K. Short- and long-term decrease of blood pressure in women during breastfeeding. Breastfeed Med. 2008;3:103-109.

31. Lee SY, Kim MT, Jee SH, Yang HP. Does long-term lactation protect premenopausal women against hypertension risk? A Korean women's cohort study. Prev Med. 2005;41:433-438.

32. Altemus M, Redwine LS, Leong YM, Frye CA, Porges SW, Carter CS. Responses to laboratory psychosocial stress in postpartum women. Psychosom Med. 2001;63:814-821.

33. Petersson M, Alster P, Lundeberg T, Uvnäs-Moberg K. Oxytocin causes a long-term decrease of blood pressure in female and male rats. Physiol Behav. 1996;60:1311-1315.

34. Petersson M, Lundeberg T, Uvnäs-Moberg K. Oxytocin decreases blood pressure in male but not in female spontaneously hypertensive rats. J Auton Nerv Syst. 1997;66:15-18.

35. World Health Organization. Protecting, promoting and supporting breastfeeding: The special role of maternity services. Available at: http://whqlibdoc.who.int/publications/9241561300.pdf. Accessed June 14, 2012.

36. World Health Organization. Global strategy for infant and young child feeding. Available at: http://www.who.int/nutrition/publications/ gs_infant_feeding_text_eng.pdf. Accessed June 14, 2012.

37. Ryan AS, Wenjun Z, Acosta A. Breastfeeding continues to increase into the new millennium. Pediatrics. 2002;110:1103-1109.

38. Ministry of Health, Labour and Welfare [http://www.mhlw.go.jp/]. Japan. Summury of the results of nutrition survey in infants (FY2005), Breast-feeding division [updated 2006 Jun 29]. Available from: [http:// www.mhlw.go.jp/shingi/2007/03/dl/s0314-17b-1.pdf (in Japanese)]. Accessed December 27, 2011. 
International Journal of Women's Health

Dovepress

\section{Publish your work in this journal}

The International Journal of Women's Health is an international, peerreviewed open-access journal publishing original research, reports, reviews and commentaries on all aspects of women's healthcare including gynecology, obstetrics, and breast cancer. Subject areas include: Chronic conditions (migraine headaches, arthritis, osteoporosis);

Submit your manuscript here: http://www.dovepress.com/international-journal-of-womens-health-journa
Endocrine and autoimmune syndromes; Sexual and reproductive health; Psychological and psychosocial conditions. The manuscript management system is completely online and includes a very quick and fair peer-review system. Visit http://www.dovepress.com/ testimonials.php to read real quotes from published authors. 